\title{
COVID-19: A case for the collection of race data in Canada and abroad
}

\author{
Emily Thompson ${ }^{1}$, Rojiemiahd Edjoc ${ }^{1 \star}$, Nicole Atchessi ${ }^{1}$, Megan Striha1', Imran Gabrani-Juma1, \\ Thomas Dawson ${ }^{1}$
}

\begin{abstract}
Racialized populations have consistently been shown to have poorer health outcomes worldwide. This pattern has become even more prominent in the wake of the coronavirus disease 2019 (COVID-19) pandemic. In countries where race disaggregated data are routinely collected, such as the United States and the United Kingdom, preliminary reports have identified that racialized populations are at a heightened risk of COVID-19 infection and mortality. Similar patterns are emerging in Canada but rely on proxy measures such as neighbourhood diversity to account for race, in the absence of person-level data. It follows that the collection of race disaggregated data in Canada is a crucial element in identifying individuals at risk of poorer COVID-19 outcomes and developing targeted public health interventions to mitigate risk among Canada's racialized populations. Given this continuing gap, advocating for timely access to this data is of great importance owing to the challenges that the COVID-19 pandemic has highlighted amongst racialized populations in Canada and worldwide.
\end{abstract}

This work is licensed under a Creative Commons Attribution 4.0 International License.

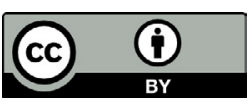

Affiliation

${ }^{1}$ Health Security Infrastructure Regional and Operations Branch, Public Health Agency of Canada, Ottawa, ON

\section{*Correspondence:}

rojiemiahd.edjoc@canada.ca

Suggested citation: Thompson E, Edjoc R, Atchessi N, Striha M, Gabrani-Juma I, Dawson T. COVID-19: A case for the collection of race data in Canada and abroad. Can Commun Dis Rep 2021;47(7/8):300-4.

https://doi.org/10.14745/ccdr.v47i78a02

Keywords: COVID-19, coronavirus, race, racialized population, visible minority, infectious disease

\section{Introduction}

Coronavirus disease 2019 (COVID-19) is an infectious disease caused by the novel severe acute respiratory syndrome coronavirus 2 (SARS-CoV-2), first identified in December 2019. On March 11, 2020, the World Health Organization declared COVID-19 a global pandemic. As of March 23, 2021, there have been more than 124 million cases and 2.7 million deaths worldwide, with 947,024 cases and 22,712 deaths in Canada alone (1).

Studies have identified several factors associated with higher infection rates and more severe outcomes of COVID-19, including a history of chronic disease, being immunocompromised and older age $(2,3)$. However, few studies have explored the impact of race on COVID-19 health outcomes. A variety of terms are used to describe racialized populations and individuals in the literature and disentangling these terms and definitions will require further dedicated research. For this article, we operationalize the term "race" as the social construct by which individuals are categorized based on perceived physical differences $(4,5)$. Other terms, such as "visible minority", "Black, Asian and minority ethnic" and "ethnically diverse", are used when the author of the study in question used such terms. We also note that the term "race" does not encompass Indigenous persons, as these communities face distinct health inequities rooted in long-standing colonialism, and the self-identification of Indigenous identity should be distinct from how these individuals are racialized by society (4).

It is impossible to discuss racial health disparities without first addressing the social determinants of health and systemic inequities that directly impact racialized populations. Studies have shown that factors such as income, employment, education and housing differ vastly between racialized and non-racialized groups (6). In particular, racialized individuals are more likely to work in low paying jobs with limited access to paid sick leave, and live in poorly maintained, unstable or crowded housing (7), all of which have been associated with poorer COVID-19 outcomes. While these issues have been pushed to the forefront because of the pandemic, it is important to recognize that they are inherently rooted in systemic racism. Systemic racism is the system by which existing policies and structures reinforce and perpetuate racial inequities (8), and has been consistently linked with poorer general and physical health outcomes (9-11). An early commentary by Yancy noted how many of the proposed COVID-19 interventions, such as physical distancing, teleworking and accepting a furlough, are issues of privilege, and may not be accessible to those in the most marginalized communities (12). These inequities are not a result of the COVID pandemic itself, 
but rather a symptom of a much more pervasive issue of racism embedded within societal policies, practices and institutions. While we are unable to provide a more thorough overview of systemic racism in this article, it is important to recognize that its impact on health care is far-reaching.

It follows that in the wake of COVID-19, disaggregated data are crucial to understanding the impact of the pandemic on diverse populations across Canada. There is increasing evidence that racialized individuals are disproportionately affected by the pandemic; emerging studies in the United States (US) and United Kingdom (UK) demonstrated an alarming trend in the burden of COVID-19 disease in these groups, including higher infection and mortality rates and more severe disease outcomes (13-15). Studies exploring the association between racialized populations and COVID-19 in Canada are limited and currently rely on proxy measures such as neighbourhood diversity rather than person-level data (16). Thus, the purpose of this article is twofold. First, it explores the effect of the COVID-19 pandemic in exacerbating already existing health inequities among racialized compared with non-racialized populations by examining downstream metrics such as COVID-19 infection and mortality rates. Second, it advocates for the refinement of the collection of race data and timely access to these datasets to better support decision-making involving racialized populations in Canada.

\section{Racialized populations and COVID-19 incidence}

Increased risk of COVID-19 infection has frequently been linked with socioeconomic factors such as poor housing and precarious employment $(10,17)$. The intersection of race, socioeconomic status and health is of particular importance to racialized persons, who consistently report higher rates of working poverty, below-standard housing and lower income (18). Preliminary reports from Public Health Ontario during the first months of the COVID-19 pandemic indicated that individuals living in ethnically diverse neighbourhoods experienced higher rates of COVID-19 disease, hospitalizations and deaths compared with less diverse neighbourhoods (19). Likewise, the Institute for Clinical Evaluative Sciences released a report detailing COVID-19 laboratory testing patterns in Ontario during the first three months of the pandemic. These early data suggest that Ontarians living in communities with the highest proportions of visible minorities or recent immigrants were three times more likely to test positive for COVID-19 than individuals living in the least diverse neighbourhoods: the most diverse communities had 10 COVID-19 cases per 100 tested individuals compared with 3.2 positive cases per 100 tested individuals in the least diverse neighbourhoods (20). Similar patterns have emerged in the US, where predominantly Black neighbourhoods are associated with an increase in positive COVID tests as compared to White neighbourhoods (21).
Racialized populations have also been cited as more likely to be essential service workers, putting them at higher risk of contracting COVID-19 due to increased exposure to infected individuals (22). In Canada, visible minorities make up approximately one third of nurse aides, orderlies and patient service associates, with higher proportions of Black, Filipino and South Asian workers in these occupations (23). This burden of labour has also become apparent in the US and UK, where racialized populations are more likely to work in low-paying service jobs with inadequate access to paid sick leave $(14,24,25)$. Finally, these factors may also have significant biological consequences on individuals' susceptibility to infection. Persistent exposure to chronic stressors, such as poor living and working conditions, has been observed to activate the hypothalamic-pituitary axis, in turn leading to greater secretion of stress hormones. Long-term exposure and the inability to regulate these hormones has been hypothesized as a contributing factor to chronic diseases $(26,27)$. For racialized populations, who already face significant differences in key health determinants as well as higher rates of comorbidity, the increased burden brought on by the COVID-19 pandemic may be driving these groups to a greater number of exposures and increased COVID-19 susceptibility.

\section{Racialized populations and COVID-19 mortality}

While person-level data on race are not readily accessible to researchers in Canada, proxies such as neighbourhood diversity have been used to study the disparities in COVID-19 deaths between racialized and non-racialized populations. A recent study from Statistics Canada linking provisional 2020 mortality data and data from the 2016 Census showed that COVID-19 mortality rates were approximately two times higher in Canadian neighbourhoods with the highest proportion of visible minorities compared with those with the lowest proportion. This contrast was especially stark in Ontario, Québec and British Columbia, where mortality rates were between three and 10 times higher in more diverse versus less diverse neighbourhoods (28). Similarly, an early report from Public Health Ontario indicated that death rates were three times higher in the most diverse neighbourhoods compared with the least diverse neighbourhoods (19). However, without access to person-level data, it is difficult to determine which groups have the highest death rates and why.

In the UK, race has been established as a strong predictor of COVID-19 mortality (29). OpenSAFELY, one of the largest running cohort studies on COVID-19-related deaths, identified that the risk of COVID-19 related deaths in Black, Asian and minority ethnic groups was nearly 1.5 times higher than White individuals, and this even after adjusting for age, sex, deprivation, and relevant comorbidities (13). In the US, despite making up less than a third of the population, Black individuals account for 
$40 \%$ to $70 \%$ COVID-19-related deaths across several cities, with mortality rates almost six times higher in predominantly Black counties than predominantly White counties (12).

It should be noted that while several studies have reported increased mortality among racialized populations, the relationship between COVID-19 mortality and race remains unclear. A review from the Emerging Sciences Group of the Public Health Agency of Canada found considerable heterogeneity among studies looking at COVID-19 mortality and race, with no significant increase in mortality risk among Black or Asian individuals (30). Moreover, further investigation is required to understand the relationship between COVID-19 morbidity and race, as long-term impacts of illness are still under investigation.

\section{Recommendations}

Understanding the relationship between COVID-19 outcomes and racialized populations has been identified as a research priority in Canada. The pandemic has brought to the forefront longstanding inequities among Canada's racialized populations, highlighting the need for race-disaggregated health data. The limited availability of Canadian data has led to few published studies on racial differences in COVID-19 outcomes and mortality (Figure 1). Proxy measures, such as neighbourhood diversity, have provided insight into COVID-19 trends between visible minorities and non-minorities (28), but further investigation is required to tease apart variations in COVID-19 outcomes among different racialized populations.

Figure 1: Number of observational studies on associations of race with risk of COVID-19 infection, severity, or mortality, by countrya, published between June $1^{\text {st }}$ and September $7^{\text {th }}, 2020$

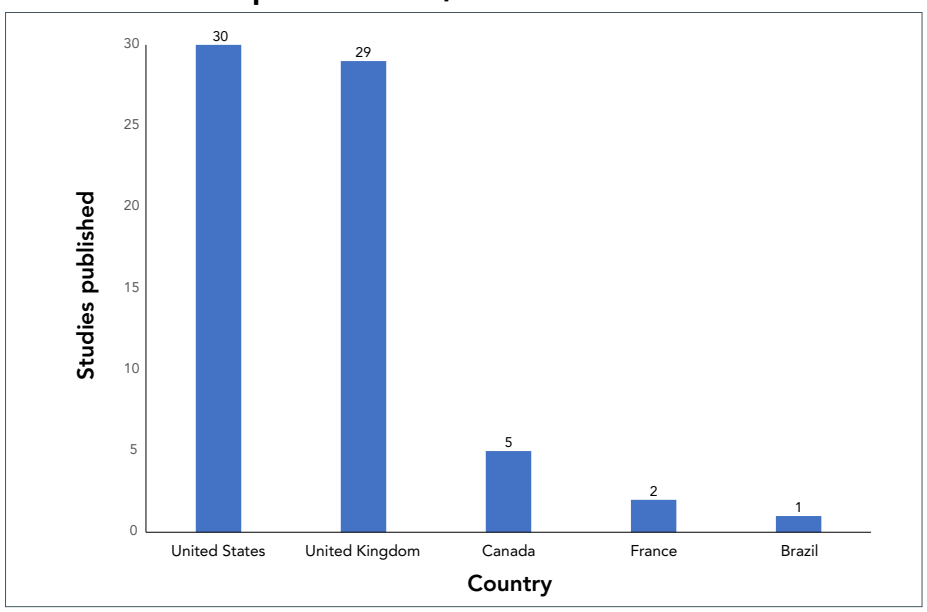

a Canadian studies also include grey literature and ecological studies (30)
We acknowledge the strain and burden of COVID-19 on local, provincial and national resources and personnel, as well as the challenge in defining key variables consistent at all levels of government. However, it is strongly recommended that continued efforts be made to refine the data collection procedure for person-level race data to provide timely access of this information to researchers to assist with policy development and public health response. As the pandemic progresses in Canada, provinces such as Manitoba and Ontario, as well as their respective regional health authorities, have indicated their intention to perform race-disaggregated data collection. Other agencies, such as the Canadian Institute for Health Information, have released proposed standards for the collection of racebased and Indigenous identity data, though further input is needed for the implementation of this project (4). We also recognize the existence of significant barriers to the collection of race data in these instances, such as increased burden on healthcare workers (31), privacy concerns (32) and data quality and utility $(32,33)$. Collaboration between provincial and federal health bodies is crucial to supporting initiatives that aim to collect person-level race data in Canada, which is a fundamental barrier in identifying care strategies to improve COVID-19 health outcomes for racialized populations and informing public policy to better support the most marginalized communities. Federal, provincial and territorial work is currently underway to standardize case reporting of commonly used terms such as race and ethnicity, to avoid misrepresentation of communities and adequate assessment of COVID-19 risk factors among different populations. To further improve upon these methods, we recommend that health institutions and researchers actively engage community members and stakeholders among the target demographics to assist in determining priorities for data collection, analysis, and reporting, as well as policy development and implementation. The collection of race-disaggregated must be undertaken with the express intent to dismantle patterns of systemic racism in health care, which can only be achieved by building racial equity within the data life cycle (34).

There are some limitations to our analysis. At this time, we were unable to undertake formal sub-analyses by gender or age, given the lack of data as well as the various ways in which race is operationalized across Canada and internationally. We note that these factors, as well as others such as socioeconomic status, housing, employment and education, are likely to impact racialized populations differently, and require further study. Finally, we did not discuss the repercussions of the COVID-19 pandemic within Canada's Indigenous populations, in recognition of the need to distinguish between racial and Indigenous identities. Indigenous peoples represent $4.9 \%$ of the population (35) and have historically had poorer health outcomes than non-indigenous Canadians $(18,36)$. Currently, data on Indigenous status and COVID-19 outcomes are collected by Indigenous Services Canada. 


\section{Conclusion}

Race disaggregated data are crucial to our understanding of how illness is experienced by the most marginalized Canadians, in terms of the COVID-19 pandemic and beyond. Mounting evidence of racial differences in COVID-19 incidence and mortality rates have emphasized the need for improved policies relating to the health of racialized populations and targeted interventions to improve COVID-19 outcomes. Efforts to collect this data in Canada are ongoing and should extend beyond the scope of the pandemic to identify disparities in healthcare and find solutions to minimize this gap.

\section{Authors' statement}

ET - Methodology, investigation, writing-original draft, review and editing

RE - Conceptualization, methodology, investigation, writingoriginal draft, review and editing, supervision

NA - Writing-original draft, review and editing

MS - Writing-original draft, review and editing

IJ - Review and editing

TD - Review and editing

\section{Competing interests}

None to declare.

\section{Acknowledgements}

We would like to acknowledge our federal, provincial and territorial partners for the ongoing work regarding in this area.

\section{Funding}

None to declare.

\section{References}

1. Dong E, Du H, Gardner L. An interactive web-based dashboard to track COVID-19 in real time. Lancet Infect Dis 2020;20(5):533-4. DOI PubMed

2. Public Health Agency of Canada. People who are at high risk for severe illness from COVID-19. Ottawa (ON): Government of Canada; 2020 (accessed 2020-20-21). https://www. canada.ca/en/public-health/services/publications/diseasesconditions/people-high-risk-for-severe-illness-covid-19.html

3. Li J, Huang DQ, Zou B, Yang H, Hui WZ, Rui F, Yee NT, Liu C, Nerurkar SN, Kai JC, Teng ML, Li X, Zeng H, Borghi JA, Henry L, Cheung R, Nguyen MH. Epidemiology of COVID-19: A systematic review and meta-analysis of clinical characteristics, risk factors, and outcomes. J Med Virol 2021;93(3):1449-58. DOI PubMed
4. Canadian Institute for Health Information. Proposed Standards for Race-Based and Indigenous Identity Data. Ottawa (ON): ClHI; 2020. https://www.cihi.ca/en/proposedstandards-for-race-based-and-indigenous-identity-data

5. National Collaborating Centre for Determinants of Health. Let's Talk: Racism and Health Equity. Antigonish (NS): NCCDH; 2018. https://nccdh.ca/resources/entry/lets-talkracism-and-health-equity

6. Nestel S. Colour Coded Health Care: The Impact of Race and Racism on Canadians' Health. Toronto (ON): Wellesley Institute; 2012. https://www.wellesleyinstitute.com/wpcontent/uploads/2012/02/Colour-Coded-Health-Care.pdf

7. Public Health Agency of Canada. Social determinants and inequities in health for Black Canadians: A Snapshot. Ottawa (ON): PHAC; 2020. https://www.canada.ca/en/publichealth/services/health-promotion/population-health/whatdetermines-health/social-determinants-inequities-blackcanadians-snapshot.html

8. Henry F, Tator C. The Colour of Democracy: Racism in Canadian Society. $4^{\text {th }}$ edition. Toronto: Nelson Education; 2010.

9. Paradies $Y$, Ben J, Denson N, Elias A, Priest N, Pieterse A, Gupta A, Kelaher M, Gee G. Racism as a Determinant of Health: A Systematic Review and Meta-Analysis. PLoS One 2015;10(9):e0138511. DOI PubMed

10. Centers for Disease Control and Prevention. Health Equity Considerations and Racial and Ethnic Minority Groups. Atlanta (GA): CDC; 2020. https://www.cdc.gov/ coronavirus/2019-ncov/community/health-equity/raceethnicity.html

11. Feagin J, Bennefield Z. Systemic racism and U.S. health care. Soc Sci Med 2014;103:7-14. DOI PubMed

12. Yancy CW. COVID-19 and African Americans. JAMA 2020;323(19):1891-2. DOI PubMed

13. Williamson EJ, Walker AJ, Bhaskaran K, Bacon S, Bates C, Morton CE, Curtis HJ, Mehrkar A, Evans D, Inglesby P, Cockburn J, McDonald HI, MacKenna B, Tomlinson L, Douglas IJ, Rentsch CT, Mathur R, Wong AY, Grieve R, Harrison D, Forbes H, Schultze A, Croker R, Parry J, Hester F Harper S, Perera R, Evans SJ, Smeeth L, Goldacre B. Factors associated with COVID-19-related death using OpenSAFELY. Nature 2020;584(7821):430-6. DOI PubMed

14. Deaton Review IF. Are some ethnic groups more vulnerable to COVID-19 than others? (accessed 2020-10-18). https:// ifs.org.uk/inequality/chapter/are-some-ethnic-groupsmore-vulnerable-to-covid-19-than-others/

15. The COVID Tracking Project. The COVID Racial Data Tracker (accessed 2020-10-23). https://covidtracking.com/race

16. Ottawa Neighbourhood Study. COVID-19 in Ottawa Neighbourhoods (accessed 2020-10-20). https:// www.neighbourhoodstudy.ca/covid-19-in-ottawaneighbourhoods/ 
17. Ahmad K, Erqou S, Shah N, Nazir U, Morrison AR, Choudhary G, Wu WC. Association of poor housing conditions with COVID-19 incidence and mortality across US counties. PLoS One 2020;15(11):e0241327. DOI PubMed

18. Public Health Agency of Canada. Key health inequalities in Canada: a national portrait - Executive Summary. Ottawa (ON): PHAC; 2018 (accessed 2020-12-04). https://www. canada.ca/en/public-health/services/publications/scienceresearch-data/key-health-inequalities-canada-nationalportrait-executive-summary.html

19. Public Health Ontario (Ontario Agency for Health Protection and Promotion). COVID-19 in Ontario - A Focus on Diversity. Toronto (ON): Queen's Printer for Ontario; 2020. https://www.publichealthontario.ca/-/media/documents/ ncov/epi/2020/06/covid-19-epi-diversity.pdf?la=en

20. Chung $H$, Fung $K$, Ferreira-Legere LE, Chen $B$, Ishiguro $L$, Kalappa G, Gozdyra P, Campbell T, Paterson JM, Bronskill SE, Kwong JC, Guttmann A, Azimaee M, Vermeulen MJ, Schull MJ. COVID-19 Laboratory Testing in Ontario: Patterns of Testing and Characteristics of Individuals Tested, as of April 30, 2020. Toronto (ON): ICES; 2020. https://www.ices.on.ca/Publications/Atlases-andReports/2020/COVID-19-Laboratory-Testing-in-Ontario

21. Whittle RS, Diaz-Artiles A. An ecological study of socioeconomic predictors in detection of COVID-19 cases across neighborhoods in New York City. BMC Med 2020;18(1):271. DOI PubMed

22. Sze S, Pan D, Nevill CR, Gray LJ, Martin CA, Nazareth J, Minhas JS, Divall P, Khunti K, Abrams KR, Nellums LB, Pareek M. Ethnicity and clinical outcomes in COVID-19: A systematic review and meta-analysis. EClinicalMedicine 2020;29:100630. DOI PubMed

23. Martin Turcotte, Katherine Savage. The contribution of immigrants and population groups designated as visible minorities to nurse aide, orderly and patient service associate occupations. Ottawa, ON: Statistics Canada; June 2020. https://www150.statcan.gc.ca/n1/pub/45-280001/2020001/article/00036-eng.htm

24. Kirby T. Evidence mounts on the disproportionate effect of COVID-19 on ethnic minorities. Lancet Respir Med 2020;8(6):547-8. DOI PubMed

25. Hutchins SS, Fiscella K, Levine RS, Ompad DC, McDonald M. Protection of racial/ethnic minority populations during an influenza pandemic. Am J Public Health 2009;99 Suppl 2:S261-70. DOI PubMed
26. Thomson EM, Kalayci H, Walker M. Cumulative toll of exposure to stressors in Canadians: an allostatic load profile. Statistics Canada; Health Reports 2019;30(6):14-21. DOI PubMed

27. McEwen BS, Stellar E. Stress and the individual. Mechanisms leading to disease. Arch Intern Med 1993;153(18):2093-101. DOI PubMed

28. Subedi R, Greenberg L, Turcotte M. COVID-19 mortality rates in Canada's ethno-cultural neighbourhoods. Ottawa (ON): Statistics Canada; Oct 2020. https://www150.statcan. gc.ca/n1/pub/45-28-0001/2020001/article/00079-eng.htm

29. Bray I, Gibson A, White J. Coronavirus disease 2019 mortality: a multivariate ecological analysis in relation to ethnicity, population density, obesity, deprivation and pollution. Public Health 2020;185:261-3. DOI PubMed

30. Public Health Agency of Canada. Emerging Sciences Group. Emerging Evidence on COVID-19: Evidence Brief on Ethnicity and COVID-19. Ottawa (ON): PHAC; Sep 2020. Full report available from: phac. ocsoevidence-bcscdonneesprobantes.aspc@canada.ca

31. Agency for Healthcare Research and Quality. Improving Data Collection across the Health Care System. Rockville, MD: Agency for Healthcare Research and Quality (accessed 2020-12-07). https://www.ahrq.gov/ research/findings/final-reports/iomracereport/reldata5.html

32. Browne AJ, Varcoe CM, Wong ST, Smye VL, Khan KB. Can ethnicity data collected at an organizational level be useful in addressing health and healthcare inequities? Ethn Health 2014;19(2):240-54. DOI PubMed

33. Varcoe C, Browne AJ, Wong S, Smye VL. Harms and benefits: collecting ethnicity data in a clinical context. Soc Sci Med 2009;68(9):1659-66. DOI PubMed

34. Nelson AL, Zanti S. A framework for centering racial equity throughout the administrative data life cycle. Int J Popul Data Sci 2020;5(1):1367. DOI PubMed

35. Statistics Canada. Statistics on Indigenous peoples. Ottawa (ON): Statics Canada; 2019 (accessed 2020-12-17). https:// www.statcan.gc.ca/eng/subjects-start/indigenous_peoples

36. Greenwood ML, de Leeuw SN. Social determinants of health and the future well-being of Aboriginal children in Canada. Paediatr Child Health 2012;17(7):381-4. PubMed 